\title{
Deformation of the 1995 North Sakhalin earthquake detected by JERS-1/SAR interferometry
}

\author{
Mikio Tobita $^{1}$, Satoshi Fujiwara ${ }^{2}$, Shinzaburo Ozawa ${ }^{1}$, Paul A. Rosen ${ }^{2}$, Eric J. Fielding ${ }^{2}$, Charles L. Werner ${ }^{2}$, \\ Masaki Murakami ${ }^{1}$, Hiroyuki Nakagawa ${ }^{1}, \mathrm{Koh} \mathrm{Nitta}^{1}$, and Makoto Murakami ${ }^{1}$ \\ ${ }^{1}$ Geographical Survey Institute, Kitasato-1, Tsukuba, Ibaraki 305-0811, Japan \\ ${ }^{2}$ Jet Propulsion Laboratory, MS 300-235, 4800 Oak Grove Dr., Pasadena, CA91109, U.S.A.
}

(Received November 14, 1997; Revised February 17, 1998; Accepted February 23, 1998)

\begin{abstract}
We present a map of the coseismic displacement field resulting from the North Sakhalin, Russia, May 28, 1995, earthquake. Raw radar signal data from the JERS-1 synthetic aperture radar instrument acquired in 28 April, 11 June, 25 July, and 7 September 1995 are used to generate a high-resolution, wide area map of the displacements by the two-pass differential interferometry method. The interferogram shows that an area of $60 \mathrm{~km}(\mathrm{EW})$ by $80 \mathrm{~km}$ (NS) experienced crustal deformations. The slip mechanism with fine structure is inverted using the displacement field of the SAR interferogram. This inversion of the SAR interferogram shows, 1) the rupture area extends to the south of the southernmost rupture trace on the surface, 2) slip varies from one to seven meters from the south to the northern part on the fault plane. A theoretical fringe pattern from the model of the earthquake motion matches the observations closely. We generate a full scene digital elevation model (DEM) by JERS-1 SAR interferometry and synthesize a four-pass interferogram. Comparison of the differential interferometry between the four-pass and two-pass interferograms shows that they are very similar and the both methods are reliable to show surface displacements using JERS-1 SAR. Correlation study of the Sakhalin interferograms indicates that low surface temperatures, below the freezing point, reduced the correlation probably because a freeze would alter the dielectric constant of the surface. In these Sakhalin interferograms, we find few spurious fringes due to the usual heterogeneous distribution of weather-related atmospheric and surface conditions, probably because of the low temperatures. We also present a map of the postseismic displacement field with the SAR interferometry.
\end{abstract}

\section{Introduction}

The North Sakhalin (or Neftegorsk) earthquake occurred on May 28, 1995. More than 2,000 people were killed in Neftegorsk, the population of which was about 3,000 (Kasahara, 1996). Shimamoto et al. (1996) reported that a right-lateral, strike-slip seismic fault ran NNE $35 \mathrm{~km}$ from $3 \mathrm{~km}$ ESE of Neftegorsk and the maximum lateral displacement was $8.1 \mathrm{~m}$. They surveyed displacements at 111 points along the fault line. Kikuchi (1996) and Takahashi et al. (1996) determined the parameters of the dislocation model using body wave analysis and position comparison between triangulation and GPS observations, respectively. These parameters had to be very simple due to limited amount of observations.

We have generated a detailed fault model based on a high resolution map of the coseismic displacement field using JERS-1 SAR interferometry. Spaceborne radars on the ERS 1 and JERS 1 satellites have been used for surface deformation studies, including coseismic deformation (Massonnet et al., 1993; Zebker et al., 1994b; Murakami et al., 1996), volcanic deflation (Massonnet et al., 1995; Rosen et al., 1996), and glacier motion (Goldstein et al., 1993) with centimeter- to millimeter-scale precision. In this paper we have applied the two-pass and four-pass methods of differential interferometry

Copy right (C) The Society of Geomagnetism and Earth, Planetary and Space Sciences (SGEPSS); The Seismological Society of Japan; The Volcanological Society of Japan; The Geodetic Society of Japan; The Japanese Society for Planetary Sciences. and have compared the results. This is the first instance of four-pass differential interferometry using JERS-1 SAR. Finally, the postseismic signature will be shown.

\section{Summary of Theory}

The theory of differential interferometry has been presented a number of times (e.g., Zebker et al., 1994b; Rosen et al., 1996). Here we derive equations on a sphere surface instead of a flat surface. Moreover, certain relations are useful to develop here that are particularly relevant to measurements by JERS-1 and are used in our processing.

When we make an interferogram from two complex images, systematic fringe pattern like stripe will be seen first. Since this systematic fringe is not necessary, this is removed from the interferogram and the phases are flattened. To flatten the interferogram, systematic fringe $\phi_{\text {sys }}$ should be subtracted from the original phase $\phi$. Then

$$
\phi_{\text {flat }}=\phi-\phi_{\text {sys }}
$$

where $\phi_{\text {flat }}$ is flattened phase. The systematic fringe $\phi_{\text {sys }}$ due to orbit difference is computed by

$$
\phi_{\mathrm{sys}}=\frac{4 \pi}{\lambda} B_{\|}
$$

where $B_{\|}$is the parallel component of the baseline (see Eq. 
(16)). Even if there is no surface displacement and no atmospheric refractivity anomalies, the flattened phase $\phi_{\mathrm{flat}}$ is not constant in an interferogram unless perpendicular component $B_{\perp}$ (see Eq. (17)) is zero. These remaining fringes affecting the whole image are due to topography. Digital Elevation Model(DEM) can be generated from this remaining phase.

To generate DEM, measured phase $\phi_{\text {flat }}$ should be related to heights $h$ above an ellipsoid through a formula. In Fig. 1, the height

$$
h=\rho d \theta \sin i_{0}
$$

is derived as a function of $d \theta$ and incidence angle $i_{0}$ (see Eq. (20)) at the ellipsoid surface.

The $d \theta$ is given by

$$
d \theta=\theta-\theta_{0}
$$

where $\theta_{0}$ and $\theta$ are look angle at the ellipsoid and surface of topography, respectively. The measured phase $\phi_{\text {flat }}$ is related to range difference $d \rho$ by

$$
\phi_{\mathrm{flat}}=\frac{4 \pi}{\lambda} d \rho
$$

This $d \rho$ is due to topography alone and is approximated by the equation

$$
d \rho \approx-\rho d \theta \varphi
$$

where $\varphi$ is calculated by

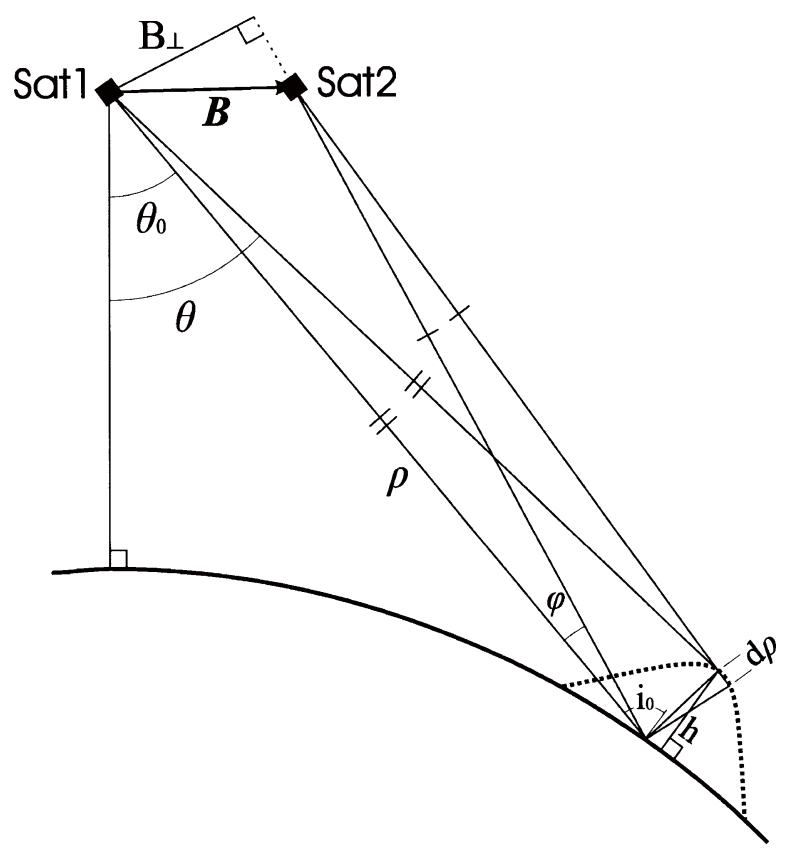

Fig. 1. Interferometric geometry. Two apertures separated by a baseline $\boldsymbol{B}$ are flying into the paper imaging a swath on the ground above an ellipsoid.

$$
B_{\perp} \approx \varphi \rho
$$

using the known perpendicular component $B_{\perp}$ of the baseline between satellite 1 and 2 . These satellites are usually the same satellite but at different time in repeat orbit. Here $\rho$ is range measured by the radar system. Because the angle $\varphi$ is very small, the above approximations are appropriate. The maximum value of the angle is

$$
\varphi_{\max }=\frac{B_{\perp \max }}{\rho} \approx \frac{1,400 \mathrm{~m}}{\rho} \approx 0.1^{\circ} .
$$

Therefore measured phase $\phi_{\text {flat }}$ can be related to heights $h$ through a formula

$$
h=-\frac{\lambda \rho \sin i_{0}}{4 \pi B_{\perp}} \phi_{\text {flat }} .
$$

To examine JERS-1 sensitivity to height, typical values described below can be used.

$$
h_{2 \pi} \approx-\frac{54,088}{B_{\perp}}(\mathrm{m}) .
$$

The sensitivity $h_{2 \pi}$ is in height per one fringe cycle. Minimum $h_{2 \pi}$ is about $38 \mathrm{~m}$ for a realistic maximum $B_{\perp} \approx 1,400$ $m$ of JERS-1 L-band SAR.

Differential interferometry, a technique by which surface deformation is measured, is a powerful method for obtaining the displacement in the direction of the radar line-ofsight with centimeter-scale precision, at decameter-scale resolution, and over hundred kilometer-scale areas. The "two-pass method" uses an existing DEM acquired by conventional means such as stereo photogrammetry to remove topography from an interferogram formed between the two passes (Massonnet et al., 1993). The "three or fourpass method" of differential interferometry generates a DEM from one interferogram as topographic reference for the other interferogram (Zebker et al., 1994b).

Consider first the two-pass method. When an existing DEM is available, we can simulate SAR interferometry from the DEM and calculate phase $\phi_{\text {flat,sim, }}$ which fringe pattern is like topographic contours. From Eq. (9), we relate the DEM height $h$ to the simulated phase by

$$
\phi_{\text {flat }, \text { sim }}=-\frac{4 \pi B_{\perp}}{\lambda \rho \sin i_{0}} h .
$$

For two-pass method of detecting surface displacement, we will have the phase

$$
\phi_{2 \text { pass }}=\phi_{\text {flat }}-\phi_{\text {flat }, \text { sim }}=\frac{4 \pi}{\lambda} \Delta \rho \text {. }
$$

If surface is not changed, the simulated phase $\phi_{\mathrm{flat}, \text { sim }}$ removes topographic phase variations, so $\phi_{2 \text { pass }}$ will be one constant color. JERS-1 sensitivity to surface change is represented by 


$$
\Delta \rho_{2 \pi}=\frac{\lambda}{2}=0.11765 \mathrm{~m}
$$

where $\Delta \rho_{2 \pi}$ denotes range difference per one fringe cycle. Thus interferometric phase is far more sensitive to surface displacement (i.e., Eq. (13)) than to topography (i.e., Eq. (10)) by about 323 times for this sensor. A phase error of $10^{\circ}$ results in a minimum topographic error of $1.1 \mathrm{~m}$ and surface displacement error of $3.3 \mathrm{~mm}$.

For the three or four-pass method of detecting surface change,

$$
\phi_{3 \text { pass }}=\phi_{\text {flat }}^{\prime}-\frac{B_{\perp}^{\prime}}{B_{\perp}} \phi_{\text {flat }}=\frac{4 \pi}{\lambda} \Delta \rho
$$

where $\phi_{\text {flat }}$ and $B_{\perp}$ are the phase and the perpendicular component of baseline of a topography-only interferogram and $\phi_{\text {flat }}^{\prime}$ and $B_{\perp}^{\prime}$ are related to the seismic interferogram. It is important to note that phase $\phi_{\mathrm{flat}}$ must be unwrapped to get results in Eqs. (9) and (14), essentially to generate an interferometric DEM. $B_{\perp}$ and $B_{\perp}^{\prime}$ are known functions of range and azimuth in a radar slant range (i.e., range) and along track (i.e., azimuth) direction coordinate system.

To simplify the processing of the two-pass method differential interferometry, the flattening procedure (i.e., Eqs. (1) and (2)) can be omitted by

$$
\phi_{\text {sim }}=\frac{4 \pi B}{\lambda} \sin \left\{\alpha-\cos ^{-1}\left(\frac{H-h}{\rho}\right)\right\}
$$

where $H$ is satellite altitude and $B$ is length (i.e., magnitude) of the baseline vector $\boldsymbol{B}$.

As described above, the baseline component $B_{\|}$must be known to remove systematic fringes due to orbit differences to flatten the phase of the interferogram (i.e., Eqs. (1) and (2)); and also $B_{\perp}$ must be known to generate a DEM (i.e., Eq. (9)) and compute differential interferometry (i.e., Eqs. (11) and (14)). $B_{\|}$and $B_{\perp}$ are functions of range and azimuth in radar coordinate system. The component $B_{\|}$is linear in azimuth and a function very similar to a quadratic curve in range direction; so the trajectory of $\phi_{\text {sys }}$, and $B_{\|}$is like Japanese fish sausage "Kamaboko." Because JERS-1 orbital information provided in parameter files accompanying the raw data has large errors, baseline components calculated from it cannot be used for accurate calculation of Eq. (2). When we process a smaller scene than a full scene, we may be able to use a Kamaboko function with inaccurate baseline information or with an empirical quadratic curve, because it is not easy to see systematic errors in the flattened phase of the small scene. This compromise, however, cannot be valid to flatten all pixels in a full scene, because systematic error due to inaccurate baseline information is evident in a large image.

Our group developed a new method to estimate baseline components very accurately to solve the problems in processing JERS-1/SAR data. The procedure is: 1) generate a simulated interferogram based on a DEM using initial tentative baseline components, 2) take the phase difference
Table 1. Typical values of JERS-1 parameters.

\begin{tabular}{ll}
\hline Radar parameter & Value \\
\hline Frequency, GHz & 1.274086 \\
Wavelength, m & 0.2353 \\
Sampling frequency, Hz & 17076000. \\
Pulse repetition frequency, Hz & 1555.2001953 \\
Pulse length, $\mu$ s & 35.0 \\
Chirp slope, Hz/s & $-0.42757 \mathrm{e} 12$ \\
Range bandwidth, MHz & 14.964950 \\
Single look range resolution, m & 10.016487 \\
Single look range spacing, m & 8.77818 \\
Ground range spacing, m & 13.8 \\
Single look azimuth resolution, $\mathrm{m}$ & $\sim 8$ \\
Single look azimuth spacing, m & $\sim 4.9$ \\
Ground azimuth spacing, m & $\sim 4.5$ \\
Typical range, m & $\sim 724,300$ \\
Typical look angle, deg & $\sim 35.7(33-38)$ \\
Typical incidence angle, deg & $\sim 39.4$ \\
\hline
\end{tabular}

between the JERS-1 interferogram and the simulated interferogram to lower the fringe rate, 3 ) unwrap phase of entire scene, 4) count residual fringes, 5) iterate 1 through 4 until residual fringes are negligible. The estimated baseline components by this method are very accurate and very useful not only for flattening but also for differential interferometry by the two-, three-, or four-pass method. We are sometimes computing the horizontal $B_{\mathrm{h}}$ and vertical component $B_{\mathrm{v}}$ of the baseline instead of $B_{\|}$and $B_{\perp}$, because $B_{\mathrm{h}}$ and $B_{\mathrm{v}}$ are constant with range (see Eqs. (18) and (19)). The definition of the baseline components are:

$$
\begin{aligned}
& B_{\|}=B \sin \left(\alpha-\theta_{0}\right) \\
& B_{\perp}=B \cos \left(\alpha-\theta_{0}\right) \\
& B_{\mathrm{v}}=B \sin \alpha \\
& B_{\mathrm{h}}=B \cos \alpha
\end{aligned}
$$

where $\alpha$ is the angle of the baseline with respect to horizontal. The incidence angle $i_{0}$ is calculated by

$$
i_{0}=\cos ^{-1}\left\{\frac{(R+H)^{2}-R^{2}-\rho^{2}}{2 \rho R}\right\}
$$

where $H$ and $R$ are the satellite altitude and the radius of the earth, respectively.

Important values of JERS-1 parameters are summarized in Table 1.

\section{Displacements Observed by SAR Interferometry 3.1 SAR data and geometry}

JERS-1 acquired SAR data of Sakhalin before and after the 1995 North Sakhalin earthquake. No other SAR sensor imaged the area spanning the earthquake. The first step of this study is searching for good pairs of imagery that have enough coherence for SAR interferometry. Tobita et al. 
(1996) processed 10 JERS-1/SAR scenes of the south Fuji area and combined the processed images to form 45 interferograms; the number is equal to all the possible combinations of the images. Nine of them had enough coherence for SAR interferometry. They concluded the possibility of having enough coherence in interferograms is about 20 percent of all possible combinations of SAR images in JERS-1 SAR data, mostly due to the random distribution of baselines.

To find interferograms that have reasonably good coherence and cover the area of the Sakhalin seismic event, full scenes of 12 SAR data (raw radar signal samples) were processed. At last, we found that three pairs, April 28, 1995June 11, 1995, July 25, 1995-September 7, 1995, and June 11, 1995-September 7, 1995 could produce interferograms that had enough, excellent, and good coherence, respectively. They are called "coseismic pair (or interferogram)", "DEM pair", and "post seismic pair" in this paper, as shown in Table 2.

Figure 2 shows a location map of these interferograms. The seismic pair covers a larger area than one typical scene, because two scenes were concatenated. The position of the epicenter shown as star in Fig. 2 was reported by USGS in 1995.

As described in the section on theory above, baseline components are critical for SAR interferometry. Table 3 summarizes the spatial baselines relevant to Sakhalin interferometry. Height per one fringe cycle denotes the JERS-1 sensitivity to height (see, Eq. (10)).

\subsection{Displacement by SAR interferometry}

Figure 3 shows a differential interferogram created using the two-pass method in UTM (Universal Transverse Mercator) projection. Equation (12), the coseismic (AprilJune) pair, and a $1 \mathrm{~km}$ spacing DEM were used to generate it. Radar line-of-sight displacements are coded in color. One cycle of interferometric phase, or "fringe", is coded as one excursion around the color wheel. The systematic fringe due to orbital difference and the topographic signature were removed using the two-pass method; thus, if the effect of atmospheric refractivity anomalies (see discussion in Section 6) is small, the remaining phase signature represents surface deformation. If the surface did not deform apprecia-

Table 2. Temporal baselines and relation to the earthquake.

\begin{tabular}{lccc}
\hline Pair & $\begin{array}{c}\text { Number of } \\
\text { 44-day cycle }\end{array}$ & $\begin{array}{c}\text { Relation to } \\
\text { the earthquake }\end{array}$ & Covering area \\
\hline April-June & 1 & coseismic & 2 full scenes \\
July-September & 1 & aseismic, DEM & 1 full scene \\
June-September & 2 & postseismic & 1 full scene \\
\hline
\end{tabular}

bly during the period of interferogram pair, we would expect to observe a uniform phase everywhere. If the surface does deform, one fringe corresponds to $11.8(11.765) \mathrm{cm}$ of surface displacement. Seismic fault lines (Takahashi et al., 1996) are superimposed in Fig. 3. The south end of the seismic fault represented in this SAR interferogram is more south than the fault line by several kilometers. The knowledge of the longer seismic fault will be useful for modeling earthquake motion (see Section 4).

Phase differences of a SAR interferometer sensitively measure changes in the line-of-sight direction. The fault motion parallel to the fault line is dominant (Shimamoto et al., 1996). Because the direction of the JERS-1 satellite velocity is nearly parallel to the fault line as shown in Fig. 3 and the line-of-sight direction is almost perpendicular to the satellite velocity, the interferometer is not very sensitive to the major coseismic lateral motion of the fault but sensitive to motions perpendicular to the fault line (e.g., vertical displacement).

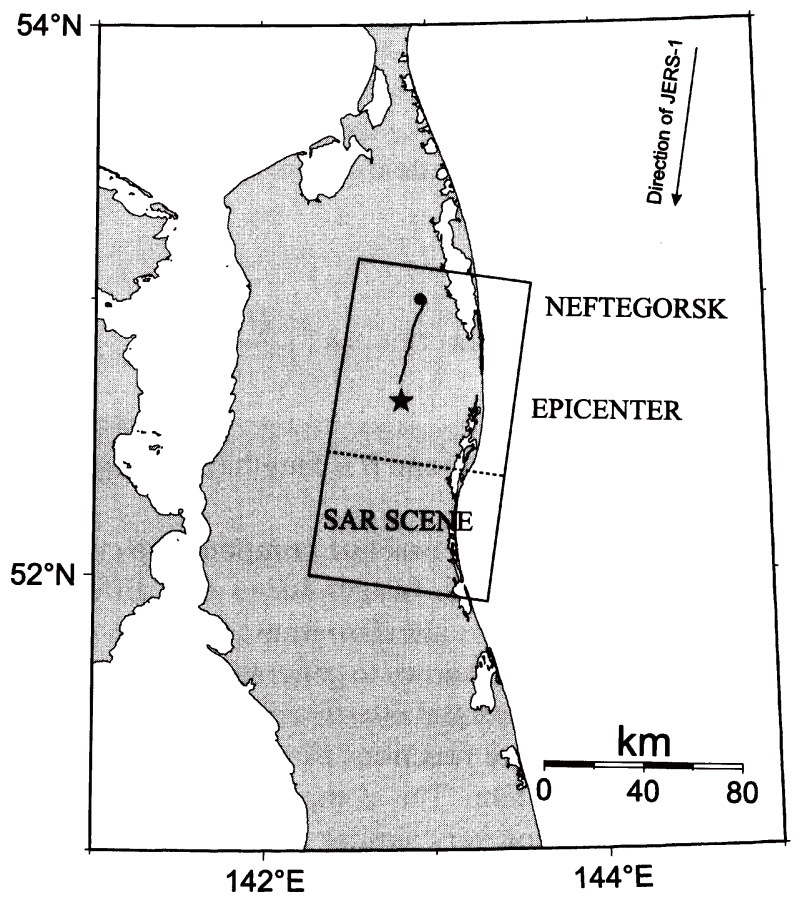

Fig. 2. Map location of three interferograms. Larger solid boundary corresponds to April-June (coseismic) interferogram pair derived from scenes concatenated along track. Broken line depicts southern boundary of July-September (DEM) and June-September (postseismic) pairs. The position of the epicenter was reported by USGS in 1995. The arrow shows the direction of the JERS-1 satellite velocity of the descending orbit. Seismic fault lines (Takahashi et al., 1996) are shown in Figs. 2, 3, 4, 8, 9, and 10, for reference.

Table 3. JERS-1 North Sakhalin interferometer spatial baseline parameters.

\begin{tabular}{lccc}
\hline & $\begin{array}{c}\text { Parallel component } B_{\|} \\
\text {Pair }\end{array}$ & $\begin{array}{c}\text { Perpendicular component } B_{\perp} \\
\mathrm{m}\end{array}$ & $\begin{array}{c}\text { Height per one fringe cycle } \\
\mathrm{m}\end{array}$ \\
\hline April-June & 489 & 257 & 210 \\
July-September & 55 & 737 & 73 \\
June-September & 375 & 540 & 100 \\
\hline
\end{tabular}




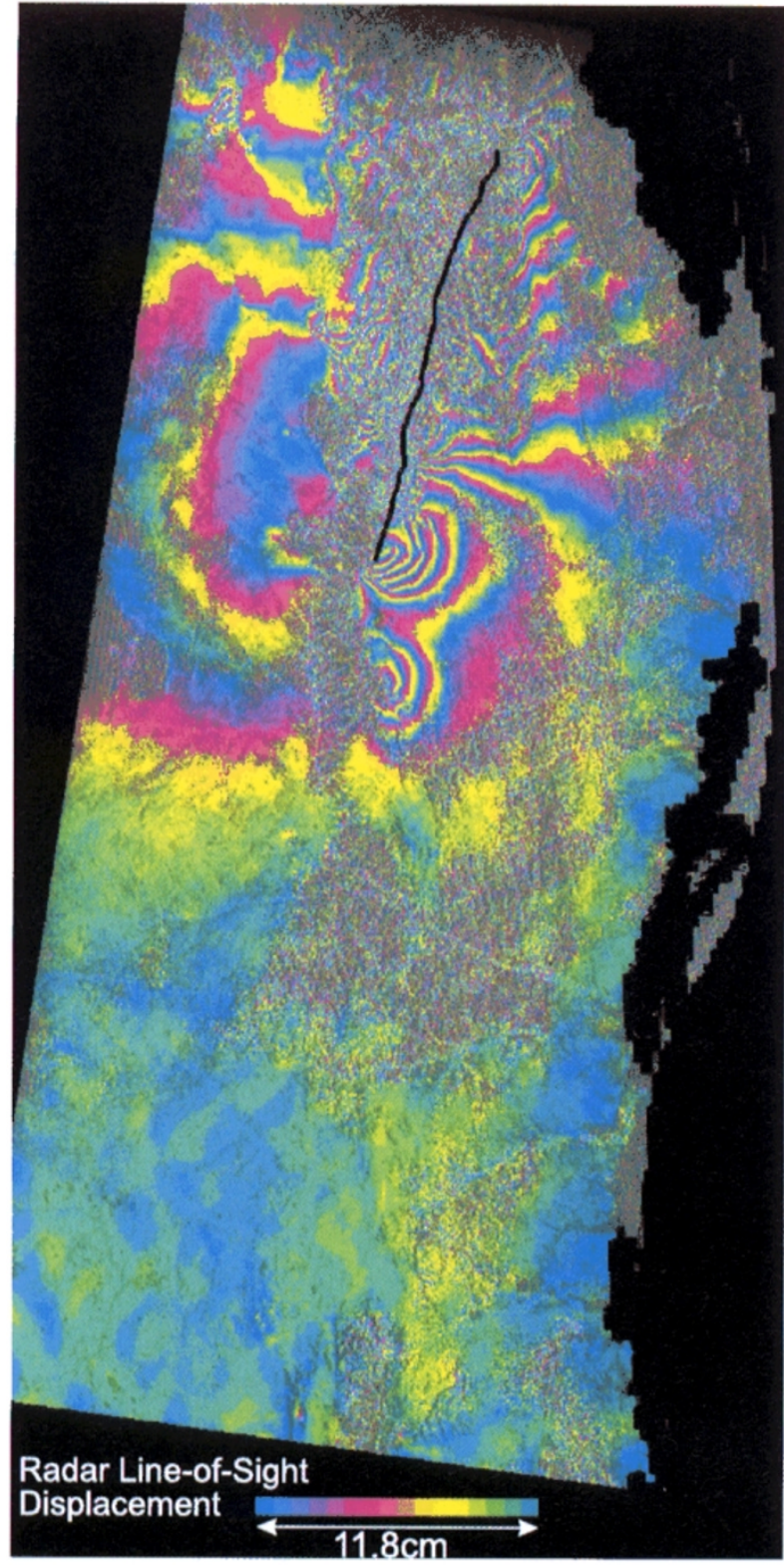

Fig. 3. Two-pass differential interferogram of North Sakhalin in UTM projection. May 28 earthquake effects are clearly evident. Radar lineof-sight displacements are coded in color, while the radar reflectivity of the surface is shown as brightness. One cycle, or "fringe", of interferometric phase is coded as one excursion around the color wheel and corresponds to $11.8 \mathrm{~cm}$ of surface displacement. Systematic and topographic fringes have been removed from the coseismic (AprilJune) interferogram. An existing DEM was used to simulate a topography-only interferogram. This phase was subtracted from the coseismic interferogram.

Figure 3 shows right-lateral, strike-slip seismic displacement clearly. An area of $60 \mathrm{~km}(\mathrm{EW})$ by $80 \mathrm{~km}(\mathrm{NS})$ experienced crustal deformation by the quake. On the east side of the seismic fault, subsidence and uplift can be seen at north and south respectively. These movements are due to the southward movement of mass. There are two peaks of line-of-sight movement on the east side of the south end of the fault line. They are both signatures which show approaching movement to the satellite (i.e., uplift or eastward motion). The amount of line-of-sight motion of north and south peaks are $82 \mathrm{~cm}$ and $47 \mathrm{~cm}$, respectively. The loca-

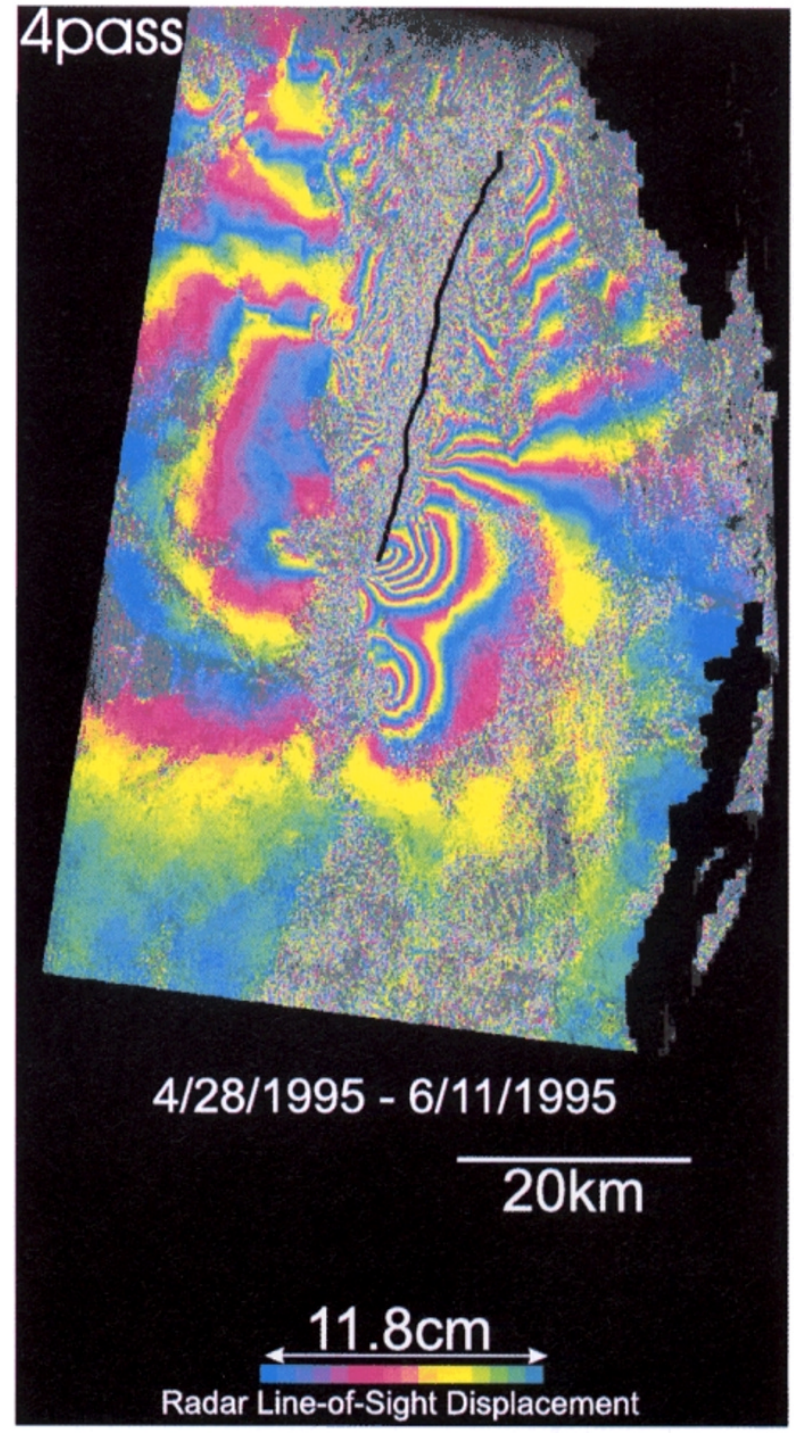

Fig. 4. Four-pass differential interferogram of North Sakhalin in UTM projection. The May 28 earthquake effects are very similar to the twopass interferogram of Fig. 3. In Eq. (14) $\phi_{\text {flat }}^{\prime}$ and $\phi_{\text {flat }}$ are of April-June (coseismic) and July-September (DEM) pair respectively.

tions of the two peaks correspond to the north and south ridges of a mountain peak. The mountain is $386 \mathrm{~m}$ high and the highest in this image. The mountain peak is at the center of two fringe peaks. In the region on the east side of the north end of the fault line, the fringes show movement away from the satellite in the line-of-sight direction (i.e., subsidence or westward motion). The amount is at least $82 \mathrm{~cm}$. Fringe trends in the region 10 to $40 \mathrm{~km}$ west of the fault line are mainly movement toward the satellite in the line-of-sight direction. The amount is about one cycle.

Some areas have unclear fringes (i.e., mixed colors). The main reason is low correlation of the areas (see Subsection 3.3). Poor fringe visibility of some areas is due to very high fringe rates. The fringe rate of C-band (e.g., ERS-1) is higher than that of L-band (e.g., JERS-1) by a factor of about 4 (the reciprocal of the wavelength ratio). In the case of large deformation like the 1995 North Sakhalin earthquake, fringe rates in the fault zone tend to be very high and L-band is more advantageous than C-band. 


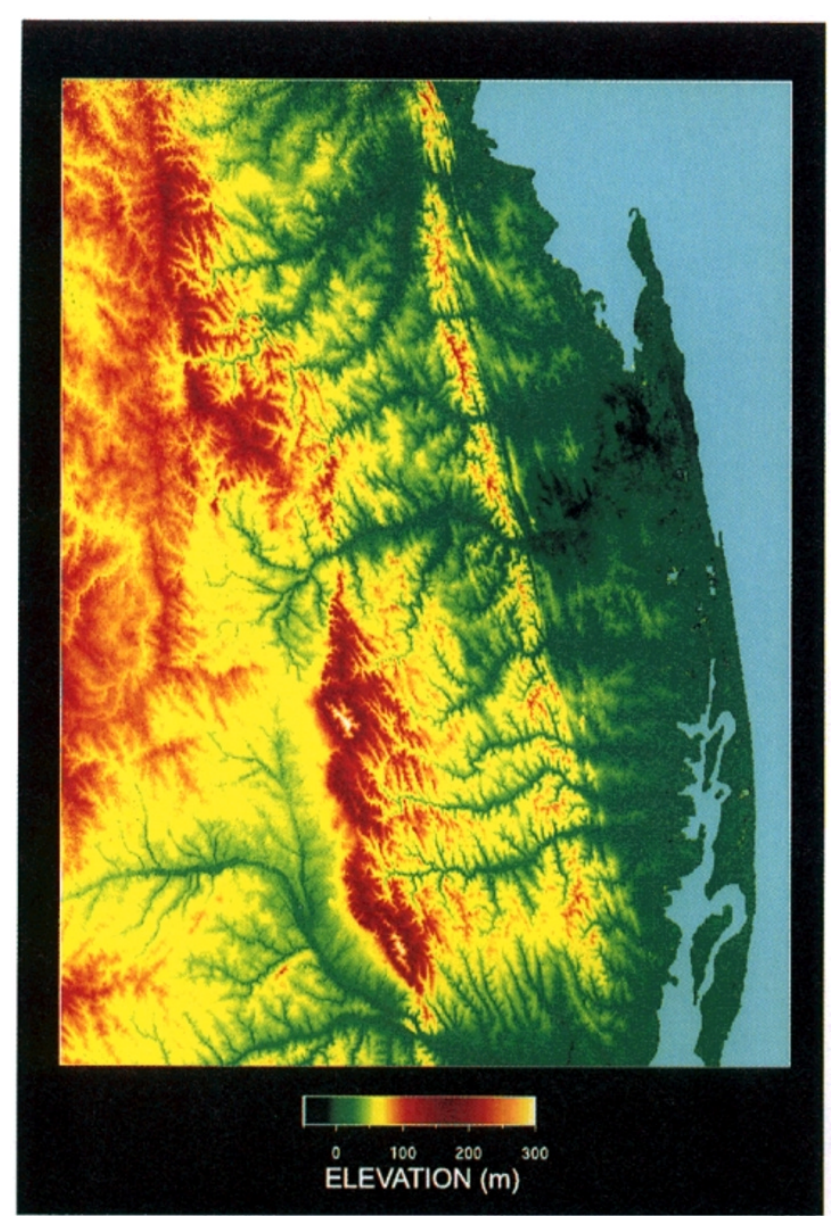

Fig. 5. DEM generated by JERS-1 SAR interferometry in radar coordinate system. July-September interferogram was first flattened by Eqs. (1) and (2), then phase was unwrapped, and finally heights were calculated by (9). This is the first complete full scene DEM using JERS-1/SAR data.
South region, where we do not expect seismic displacement, has constant color (i.e., constant phase). This proves that our estimation of the baseline is good, and the effect of anomalous propagation on the phase is smaller than a quarter-cycle. This fact proves that the phase noise is less than quarter cycle (i.e., $3 \mathrm{~cm}$ ) throughout the image and the signatures of coseismic displacements along the fault line are reliable at this level.

Figure 4 shows a four-pass interferogram derived by Eq. (14). This is the first three/four-pass interferogram provided by JERS-1 SAR. To make this, we generated a DEM by SAR interferometry (Eq. (9)). As shown in Fig. 5, our DEM meets the necessary resolution and accuracy for the four-pass method. We unwrapped phases by the method of Hiramatsu (1992). This time, phase unwrapping is completely successful. Typically, holes due to impossible phase unwrapping cannot be avoided and the holes are interpolated.

In this paper we can compare the four-pass interferogram (Fig. 4) with the two-pass interferogram (Fig. 3) described above. As can be seen, they are very similar. Of course, the phases in some areas differ in the two interferograms, but the difference is about $3 \mathrm{~cm}$ at most. The main reason of this difference is that the $1 \mathrm{~km}$ spacing DEM is inaccurate. The amount of this difference is consistent with the error estimated from the DEM inaccuracy, which will be discussed in Section 6. This is the first comparison of results from two different methods of differential interferometry for measuring surface change in JERS-1 SAR. This comparison proves that both are useful for showing surface displacements using JERS-1 SAR data, though these two approaches use different data each other as described in Section 2.

\subsection{Correlation of the interferogram}

An important factor in the interferometric technique is coherence, or correlation, because correlation is an index of phase stability. Stability of measured phase has direct relation to the precision of surface change measurement through Eqs. (12) and (14). If the coherence of SAR interferometer is not sufficient, signatures in an interferogram make no
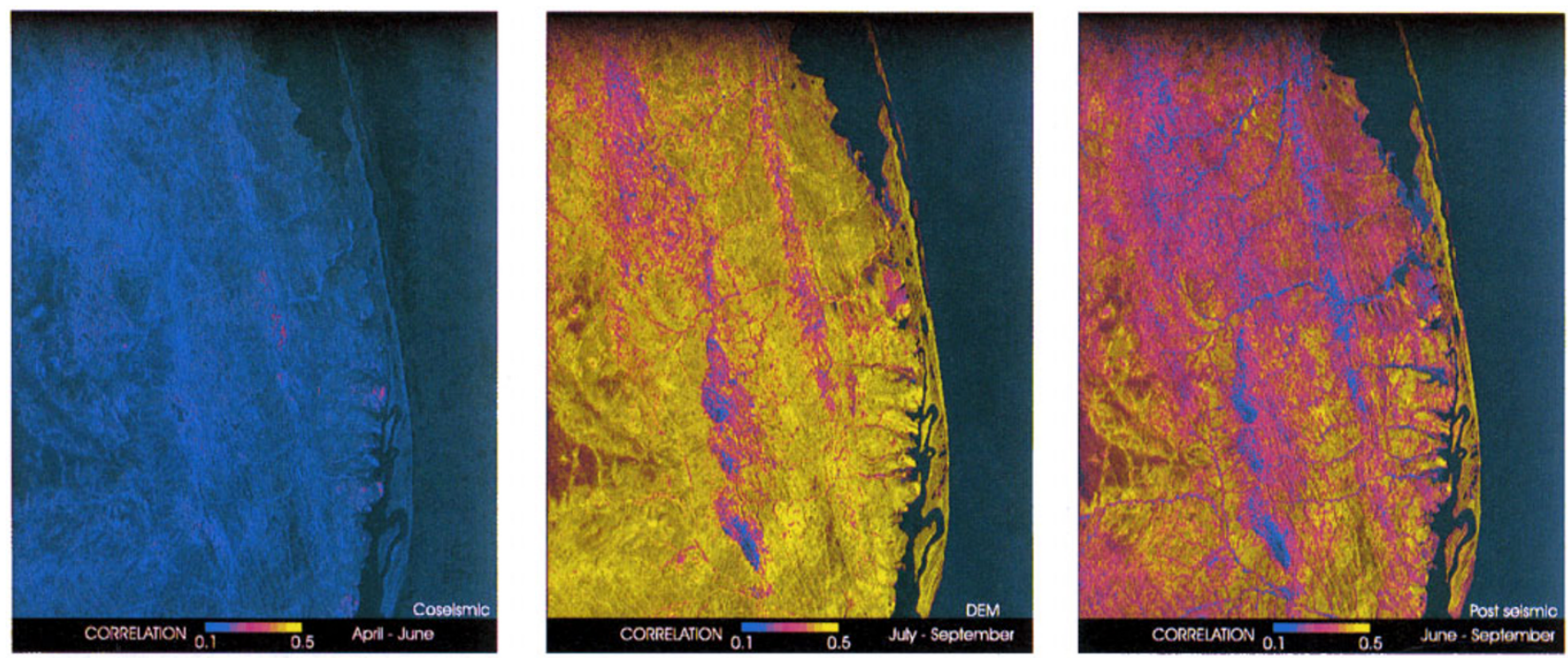

Fig. 6. Correlation coefficient maps of interferograms of coseismic, DEM and postseismic pair in UTM projection. (left) April-June; (middle) JulySeptember; (right) June-September. These images are in a radar slant range (i.e., range) and along track (i.e., azimuth) direction coordinate system. 
sense. Because the probability that we get an interferogram with good coherence is only about $20 \%$ for JERS-1, accessing the database, requesting SAR data, shipping huge data sets, and processing them without coherence knowledge in advance are a waste of time and resources. Correlation study helps us to find good coherence data swiftly and to estimate measurement errors.

Typical sources of the decorrelation are steep slope of topography, long spatial baseline, and long temporal baseline. A more detailed discussion can be seen in Fujiwara et al. (1998).

The correlation coefficient at each of the multilook pixels is calculated according to

$$
\rho=\frac{\left|\left\langle c_{1} c_{2}^{*}\right\rangle\right|}{\sqrt{\left\langle c_{1} c_{1}^{*}\right\rangle\left\langle c_{2} c_{2}^{*}\right\rangle}}
$$

where $c_{1}$ and $c_{2}$ are the corresponding complex values from two images and $<>$ denotes summation in a multilook window. If an area has a high (i.e., good) correlation value, this area will be shown as a constant color (i.e., phase) in an interferogram. High correlation means precise measurement of surface changes.

Figure 6 shows correlation coefficient maps corresponding to interferograms of coseismic, DEM and postseismic pair in radar coordinate system. The April-June pair has poor correlation. Tobita et al. (1996) and Fujiwara et al. (1998) reported a strong relation between the spatial baseline $B_{\perp}$ and correlation. The correlation declines linearly with the spatial baseline for surfaces without relief. Because $B_{\perp}$ of the April-June pair, $257 \mathrm{~m}$, is not longer than that of JulySeptember pair, $737 \mathrm{~m}$, this decorrelation case is not due to spatial baseline decorrelation. Next, we suspected that large ground shifts could result in lack of precision alignment of the pixels from pass to pass. We tried coregistration of small patches separately, but correlation could not be improved. Moreover, decorrelation is not spatially dependent. The southern region, where movement from the earthquake is rather small compared to the region near fault line, also has poor correlation, for example. Thus the earthquake displacement is not the main reason for poor correlation.

Tobita et al. (1996) also reported that $10 \mathrm{~cm}$ snow cover significantly reduced correlation. Figure 7 shows radar amplitude (radar backscatter image) of April, June, July and September data. There is a big difference between April and the other three data. Only the April image has sea ice. Usually, North Sakhalin coast is covered by sea ice from November through May. The temperature was probably below freezing in the April image. The ground was possibly covered with snow. Zebker et al. (1994a) studied ERS-1 correlation and pointed out that a freeze would alter the dielectric constant of the surface and could be expected to have a major impact on the complex reflectivity of the surface. Therefore, the reason for poor correlation of the April-June pair is likely from a different dielectric constant of the April image from the other three images.

\section{Fault Model Constrained with the SAR Inter- ferometry}

Okada (1985) formulated surface displacements from a buried fault in an infinite half space elastic medium by using 10 fault parameters as follows:

$\boldsymbol{u} \boldsymbol{x}=\boldsymbol{u} \boldsymbol{x}\left(U_{1}, U_{2}, U_{3}\right.$, strike, dip, depth, width, length, $\left.x_{0}, y_{0}\right)$

$\boldsymbol{u y}=\boldsymbol{u} \boldsymbol{y}\left(U_{1}, U_{2}, U_{3}\right.$, strike, dip, depth, width, length, $\left.x_{0}, y_{0}\right)$

$\boldsymbol{u} \boldsymbol{z}=\boldsymbol{u} \boldsymbol{z}\left(U_{1}, U_{2}, U_{3}\right.$, strike, dip, depth, width, length, $\left.x_{0}, y_{0}\right)$

where $\boldsymbol{u} \boldsymbol{x}, \boldsymbol{u} \boldsymbol{y}$, and $\boldsymbol{u} \boldsymbol{z}$ represent north-south, east-west, and up-down components of ground displacements, respectively. $U_{1}, U_{2}$, and $U_{3}$ are strike slip, dip slip and tensile components on a buried fault. Strike, dip, width, and length are strike, dip angles, width and length of a rectangular fault respectively. $x_{0}, y_{0}$, and depth represent coordinates at the lower left corner of a buried fault. By using Okada's formula, we can write down an observation equation of a SAR interferogram as follows:
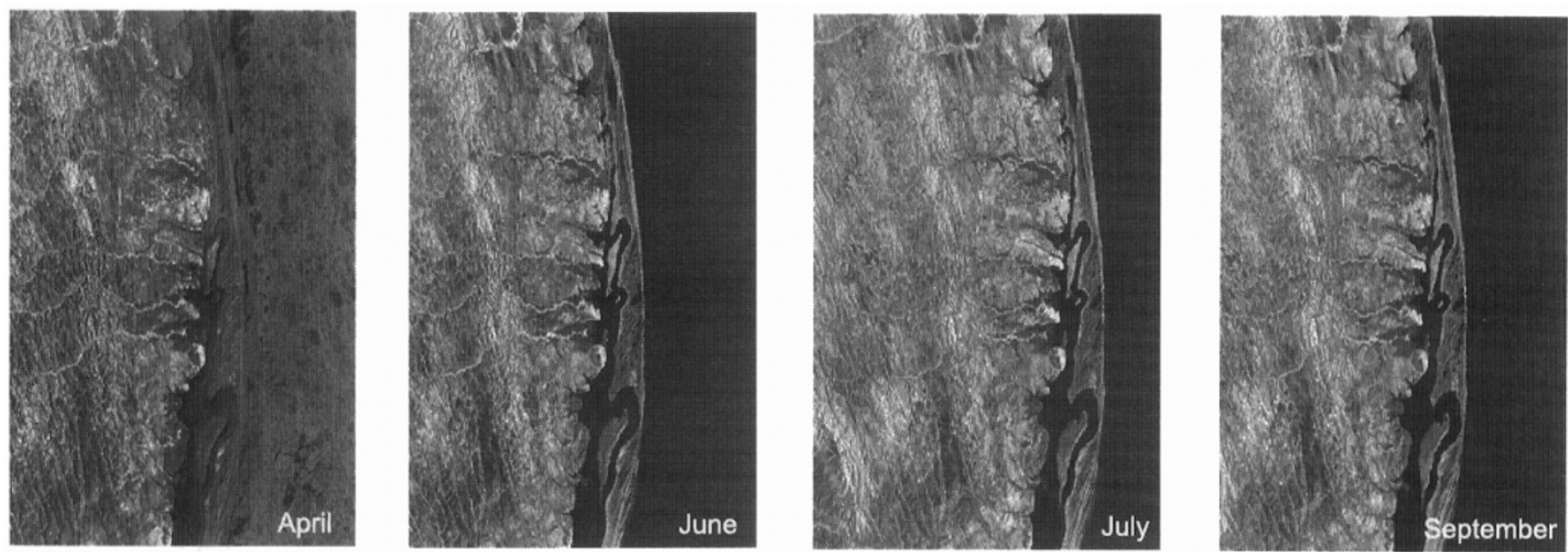

Fig. 7. Radar amplitude images. The radar reflectivity of the surface is shown as brightness. (left) April 28, 1995; (middle left) June 11, 1995; (middle right) July 25, 1995; (right) September 7, 1995. Only April image has sea ice. These images are in a radar slant range (i.e., range) and along track (i.e., azimuth) direction coordinate system. 


$$
\boldsymbol{d}=\boldsymbol{u} \cdot \boldsymbol{n}+c
$$

where $\boldsymbol{u}$ represents a displacement vector due to slip on a buried fault under the ground. $\boldsymbol{n}$ is a unit vector of the satellite line-of-sight. $c$ is a constant term. $\boldsymbol{d}$ represents observations. A typical value of the unit vectors along the fault line in the local coordinate system in this study is (North, East, Up $)=(-0.07643,0.62247,0.77890)$.

By employing a linearized least squares method, we estimate nine fault parameters from SAR interferogram data with a tensile component fixed at 0.0 in this study (Ozawa et al., 1997).

When there are several constraints on a configuration among subfaults, we incorporate a condition equation into the least squares adjustment. For example, if two faults have the same width, the following equation is satisfied:

$$
\text { width }_{1}=\text { width }_{2}
$$

where the subscript distinguishes each fault. By incorporating condition equations such as Eq. (22), we estimate optimal parameters under several constraints on parameters (Mikhail, 1976). We give a weight of $5 \mathrm{~cm}$ for $S A R$ interferogram data, considering the error budget discussed in Section 6, which error is smaller than $5 \mathrm{~cm}$. We sampled the SAR data with spacing of between 1 and $2 \mathrm{~km}$, taking care of not to lose characteristic features in the interferogram (Fig. 3).

As a starting point, a fault system consisting of 4 subfaults is used to regress SAR interferogram data. Figure 8 shows a configuration of four subfaults. We number each fault in order from the north to the south, as shown in Fig. 8. Each subfault is tied to another at the upper edge points in Fig. 8. Without any constraints, each subfault tends to dip to the east, which is inconsistent with the seismic wave studies and field surveys. In order to constrain the dip angle of faults, we incorporate dummy data of dip angle of $79^{\circ}$ with an error of $3^{\circ}$, which is derived from the results of Kikuchi et al. (1996).

Since the surface rupture of this earthquake was traced in detail by Shimamoto et al. (1996), we use this a priori information to place each subfault. The northern upper corner of the first fault is fixed at the location of the north end of the surface rupture mapped by Shimamoto et al. (1996). The strike angle is set at $204^{\circ}$, which is estimated from the fault trace on the surface. The length is set at $14 \mathrm{~km}$ to match the fault trace on the surface.

The strike angle of the second fault is set at $194^{\circ}$ parallel to the mapped fault, by incorporating highly weighted dummy data of strike angle. The third fault has the same width, the same strike and dip angles with those of the second fault, constituting one plane together. By using these two faults, we take into consideration a variation of slip along this relatively long section. The last subfault is tied to the third one at the upper edge corner and set free with respect to strike angle.

Under these conditions, we estimated the optimal parameters of this four subfault system. Table 4 shows estimated optimal parameters. The resulting configuration of four subfaults is shown in Fig. 8 together with the surface rupture

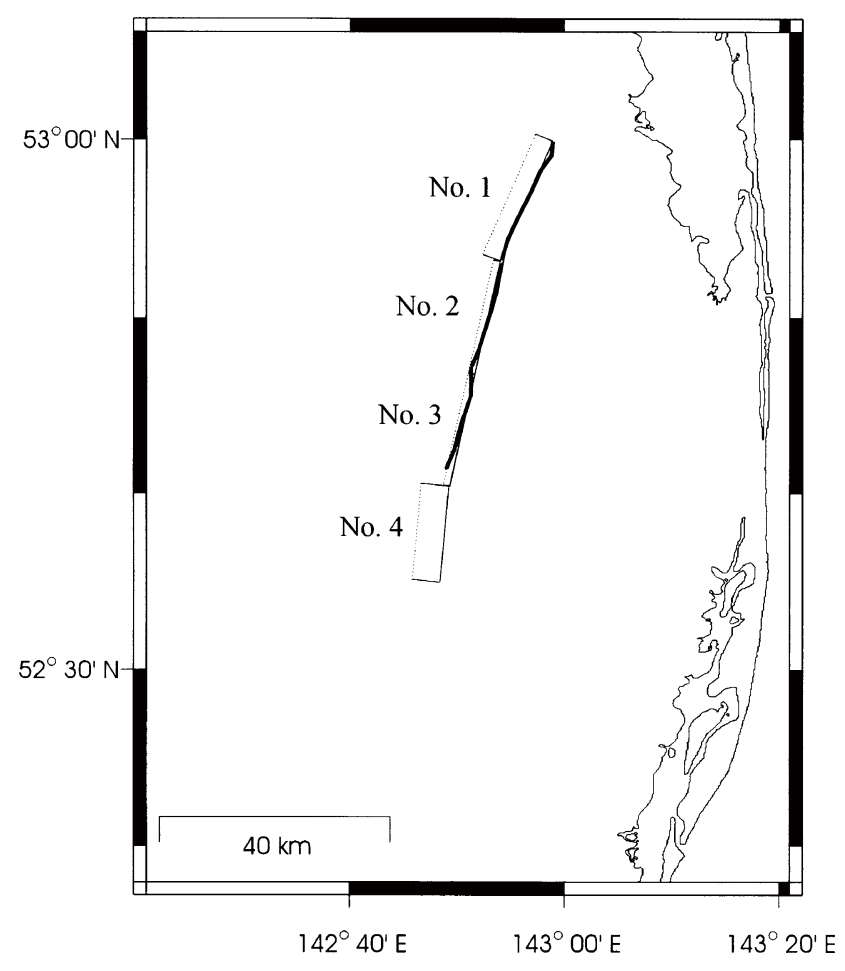

Fig. 8. Location map of estimated four subfaults obtained by inverting SAR interferogram data. Each rectangle represents a fault. Dotted line on rectangle indicates the bottom edge of fault plane. The number of each fault corresponds to that in Table 4. Solid line shows the location of the mapped earthquake fault by Shimamoto et al. (1996).

Table 4. Optimal fault parameters of four subfaults estimated from regression of SAR interferogram. $U_{1}$ and $U_{2}$ represent strike slip and dip slip in meters. Lat., Lon., and depth are latitude, longitude, and depth of a lower left corner of each fault. Strike, dip, width, and length are strike angle, dip angle, width and length of a rectangular fault. Number of each fault corresponds to the number in Fig. 8. Bold letters represent estimated values

\begin{tabular}{|c|c|c|c|c|c|c|c|c|}
\hline & No. 1 & $\sigma$ & No. 2 & $\sigma$ & No. 3 & $\sigma$ & No. 4 & $\sigma$ \\
\hline$U_{1}, \mathrm{~m}$ & -3.3 & 0.15 & -4.3 & 0.06 & -1.2 & 0.1 & -1.0 & 0.09 \\
\hline$U_{2}, \mathrm{~m}$ & 0.4 & 0.04 & 0.06 & 0.06 & -1.5 & 0.07 & -0.5 & 0.05 \\
\hline Lat., ${ }^{\circ}$ & 53.0056 & 0.06 & 52.8880 & 0.01 & 52.7278 & 0.02 & 52.6766 & 0.1 \\
\hline Lon., ${ }^{\circ}$ & 142.9546 & 0.10 & 142.8894 & 0.06 & 142.83 & 0.04 & 142.7763 & 0.1 \\
\hline strike, ${ }^{\circ}$ & 203.9 & 0 & 192.8 & 0.2 & 192.8 & 0.2 & 185.6 & 2.1 \\
\hline $\operatorname{dip},^{\circ}$ & 83.4 & 0.5 & 85.8 & 0.4 & 85.8 & 0.4 & 82.5 & 0.5 \\
\hline depth, km & 16.8 & 0.02 & 9.1 & 0.02 & 9.1 & 0.017 & 22.3 & 0.1 \\
\hline width, km & 16.9 & 0.01 & 9.16 & 0.02 & 9.16 & 0.017 & 22.7 & 0.1 \\
\hline length, km & 13.6 & & 18.3 & 0.02 & 5.99 & 0.03 & 10.1 & 0.4 \\
\hline
\end{tabular}
in a linearized least squares fit. $\sigma$ corresponds to one standard deviation. 
trace. From this computation, we estimated places of ruptured area of the 1995 North Sakhalin earthquake, as shown in Fig. 8. After estimating ruptured areas by this four fault system, we examined a detailed slip distribution by dividing these four faults into two or three parts along striking. In this inversion, free parameters are only strike slip and dip slip components on each subfault. The other parameters are fixed so that divided subfaults constitute the four-faults system in Fig. 8 in all. Since crustal deformation depends on slip parameters linearly, we can estimate slip distribution by linear least squares fitting in this case. The estimated optimal parameters are summarized in Table 5.

Our result shows the following features. Firstly, the southernmost subfault extends to the south from the south end of the surface rupture by about $15 \mathrm{~km}$, as shown in Fig. 8. This configuration is in agreement with the aftershock distribution, which also covers the area south of the mapped fault line. Several researchers expect a break of the southern part underneath the ground, considering the aftershock distribution and the difference between moment releases based on seismic wave study and that calculated from a mapped rupture trace. Table 5 shows the variation of slip from one to seven meters increasing to the north. Shimamoto et al. (1996) measured the right lateral displacements revealed on the surface at about 110 points. Their result indicates an increase of right lateral displacement from the southern end of the surface rupture to $20 \mathrm{~km}$ north with a maximum of about $8 \mathrm{~m}$ and a gradual decrease further to the north. The average slip is about $3.8 \mathrm{~m}$ according to Shimamoto et al. (1996). A wave form inversion by Kikuchi et al. (1996) shows that there occurred two events at the time of the 1995 North Sakhalin earthquake. Rupture was initiated at the southern part and propagated to the north. A subevent in the southern part released one third of a moment of the northern subevent, indicating a smaller slip in the south. Average slip on a seismic fault is estimated at $3.1 \mathrm{~m}$ assuming a rupture area of $30 \mathrm{~km}$ in length and $15 \mathrm{~km}$ in width.

Our resulting model shows a similar slip distribution compared with that of a field survey and a wave form inversion in that slip increases to the north from the south.

Since static ground displacement from a fault movement decays rapidly with distance, traditional spacially sparse survey do not provide enough information to estimate slip distribution with high resolution. On the contrary, SAR interferograms detect crustal deformation in quasi two dimensional way, we can estimate a finer structure than those of models derived from GPS or other traditional surveys. Our estimated fault model shows the extension of rupture area to the south from the southern end of the surface rupture. This type of information can be derived only by utilizing spatially dense SAR interferogram data, showing the remarkable effectiveness of SAR interferogram to investigate an earthquake process. Though our present model does not fully employ a huge amount of information in SAR interferogram yet, we could reach a relatively detailed model which is consistent with seismic studies and field surveys with less assumption on the model.

Figure 9 shows a simulated SAR interferogram based on our optimal model. This image reproduces characteristic features of the observed SAR interferograms such as two peaks in the southern part of the traced fault line (i.e., Figs. 3 and 4). Minute difference between the model and the observation seems to be derived from the ignorance of slip variation with depth and not so fine slip distribution along striking of our model. With regard to these points, more improvements of our model is still necessary. In summary, present inversion study of SAR interferogram shows, 1) a rupture area extends to the south of the southernmost rupture

Table 5. Estimated slip parameters on 12 subfaults. Symbols are the same as those in Table 4. Figure in bracket represents one sigma. For example, $-2.6(5)$ denotes $-2.6 \pm 0.5$. $U_{1}$ and $U_{2}$ are estimated by regressing SAR data.

\begin{tabular}{|c|c|c|c|c|c|c|}
\hline Fault id & 1 & 2 & 3 & 4 & 5 & 6 \\
\hline$U_{1}, \mathrm{~m}$ & $-4.8(3)$ & $-3.2(3)$ & $-7.1(4)$ & $-4.1(3)$ & $-5.4(5)$ & $-4.0(6)$ \\
\hline$U_{2}, \mathrm{~m}$ & $1.0(2)$ & $-0.2(1)$ & $0.1(2)$ & $0.7(4)$ & $3.1(5)$ & $1.7(3)$ \\
\hline Lat., ${ }^{\circ}$ & 53.0056 & 52.9683 & 52.9310 & 52.8880 & 52.8480 & 52.8079 \\
\hline Lon., ${ }^{\circ}$ & 142.9546 & 142.9272 & 142.8999 & 142.8894 & 142.8745 & 142.8596 \\
\hline Strike, ${ }^{\circ}$ & 203.9 & 203.9 & 203.9 & 192.8 & 192.8 & 192.8 \\
\hline Dip, ${ }^{\circ}$ & 83.4 & 83.4 & 83.4 & 85.8 & 85.8 & 85.8 \\
\hline Depth, km & 16.8 & 16.8 & 16.8 & 9.1 & 9.1 & 9.1 \\
\hline Width, km & 16.9 & 16.9 & 16.9 & 9.2 & 9.2 & 9.2 \\
\hline Length, km & 4.5 & 4.5 & 4.5 & 4.6 & 4.6 & 4.6 \\
\hline
\end{tabular}

\begin{tabular}{|c|c|c|c|c|c|c|}
\hline Fault id & 7 & 8 & 9 & 10 & 11 & 12 \\
\hline$U_{1}, \mathrm{~m}$ & $-2.2(5)$ & $-1.8(4)$ & $-2.2(3)$ & $-1.6(3)$ & $-1.1(2)$ & $-0.2(2)$ \\
\hline$U_{2}, \mathrm{~m}$ & $-0.4(2)$ & $-1.1(2)$ & $-2.7(3)$ & $1.5(2)$ & $-0.4(1)$ & $0.0(1)$ \\
\hline Lat., ${ }^{\circ}$ & 52.7679 & 52.7278 & 52.7016 & 52.6766 & 52.6464 & 52.6163 \\
\hline Lon., ${ }^{\circ}$ & 142.8448 & 142.8300 & 142.8203 & 142.7763 & 142.7716 & 142.7669 \\
\hline Strike, ${ }^{\circ}$ & 192.8 & 192.8 & 192.8 & 185.6 & 185.6 & 185.6 \\
\hline Dip, ${ }^{\circ}$ & 85.8 & 85.8 & 85.8 & 82.5 & 82.5 & 82.5 \\
\hline Depth, km & 9.1 & 9.1 & 9.1 & 22.3 & 22.3 & 22.3 \\
\hline Width, km & 9.2 & 9.2 & 9.2 & 22.7 & 22.7 & 22.7 \\
\hline Length, km & 4.6 & 3.0 & 3.0 & 3.4 & 3.4 & 3.4 \\
\hline
\end{tabular}




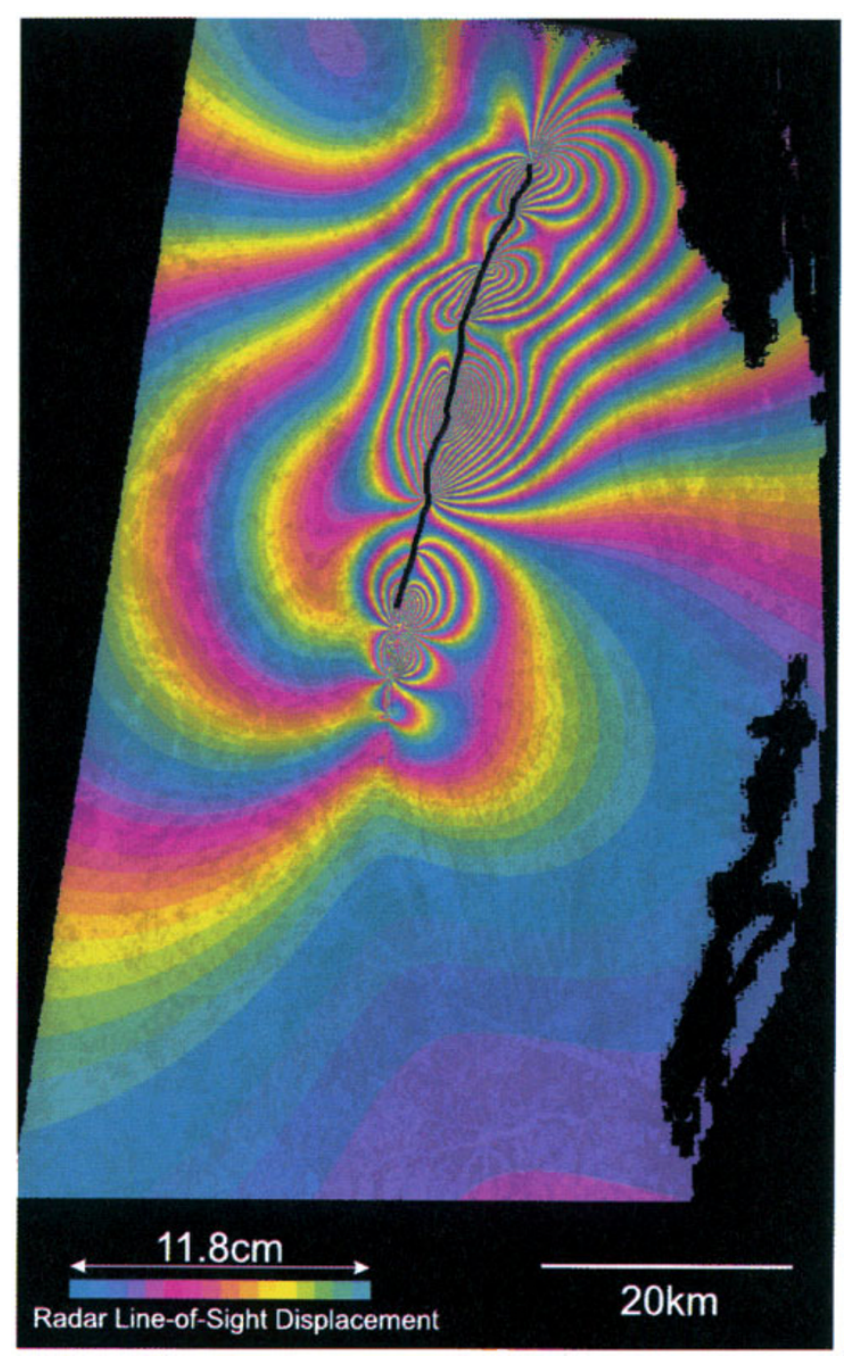

Fig. 9. Simulated interferogram based on our optimal fault model. This image matches the observed interferogram (Figs. 3 and 4) fairly closely.

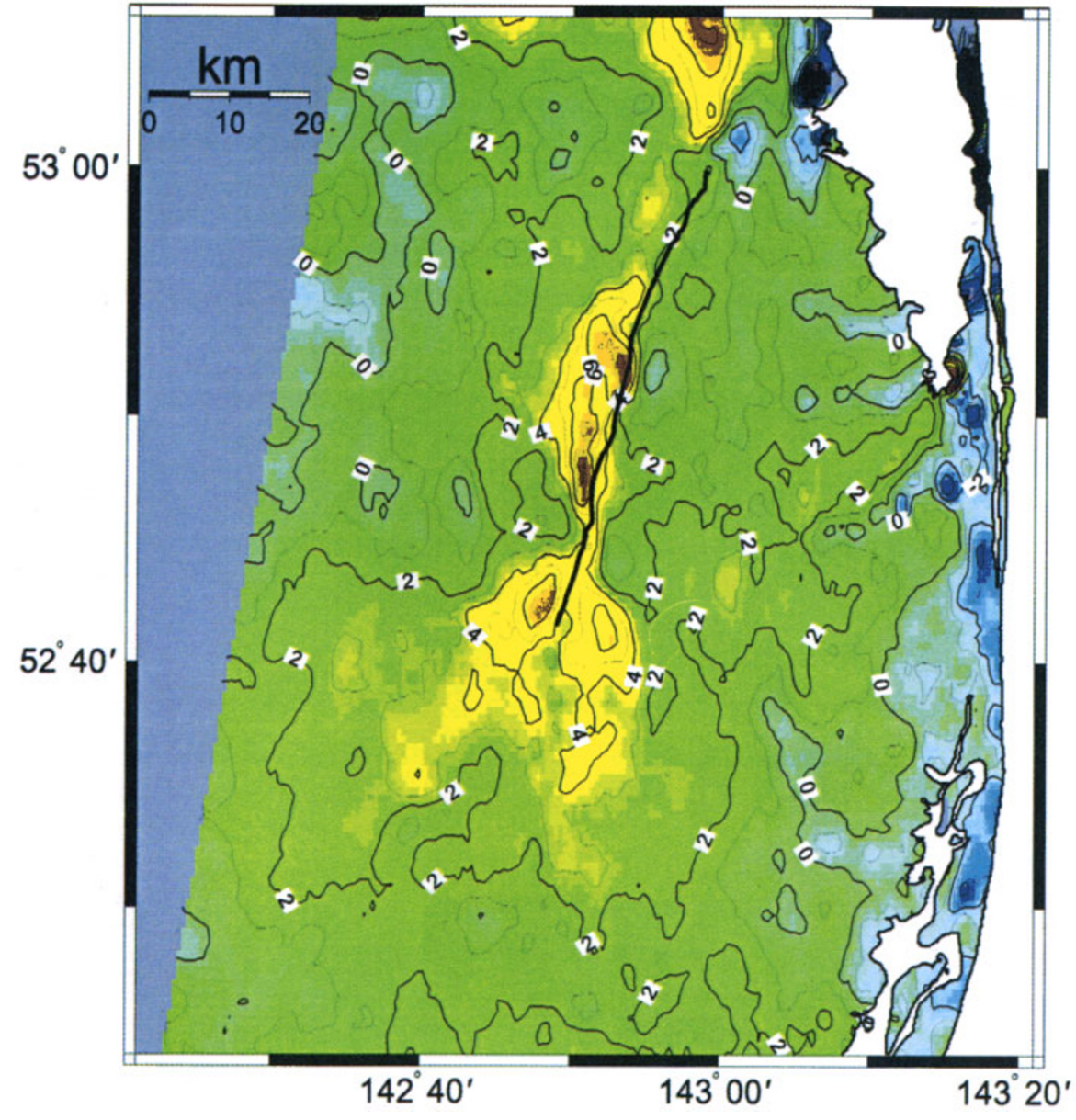

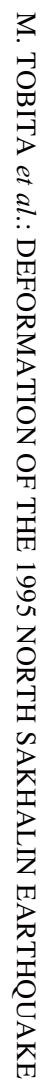

Fig. 10. Four-pass differential interferogram of North Sakhalin in UTM projection. The post seismic displacement June through September can be seen. In Eq. (14) $\phi_{\text {flat }}^{\prime}$ and $\phi_{\text {flat }}$ are of June-September (postseismic) and July-September (DEM) pair respectively. The numbers with plus sign (i.e., red color) represents movement toward the satellite in the line-of-sight direction. 
trace on the surface, 2) slip varies from one to seven meters from the south to the northern part on a fault plane.

\section{Postseismic Deformation}

Figure 10 shows a map of the postseismic displacements of the ground in the radar line-of-sight direction, where the shift is coded in color and contour lines represent line-ofsight displacement spaced every $1 \mathrm{~cm}$. The phases in the map were unwrapped, while coseismic displacement maps (i.e., Figs. 3 and 4) could not be unwrapped due to strong decorrelation and high fringe rate.

The interferogram shown in Fig. 10 covers 88 days after the main shock, starting on June 11, 1995 (i.e., 14 days after the main shock). Signatures along the seismic fault line are movements toward the satellite. The maximum line-of-sight displacement, $8.5 \mathrm{~cm}$, corresponds to $13.4 \mathrm{~cm}$ of uplift, if the motion is purely uplift. In the northern region of the north end of the seismic fault line, signatures in the east and west side can be subsidence and uplift, respectively. This can be interpreted as the motion that continues the mass movement due to the right-lateral motion. There may be a hidden fault plane under ground in this region and were active as a rightlateral fault after the main shock.

Unfortunately, June-July pair could not be used for postseismic study, because the perpendicular component of the baseline is larger than 1,200 $\mathrm{m}$ and the interferogram of this pair is completely decorrelated.

\section{Discussion (Error Estimation)}

JERS-1 suffers from a low signal level because the radar transmitter on board the spacecraft must be operated at a power level reduced from its design specification for technical reasons. Murakami et al. (1996) examined phase errors in Northridge interferogram of JERS-1 SAR. The standard deviation of the phase was $1.0 \mathrm{~cm}$. We sampled a few hundreds pixels in a rectangle of our Sakhalin interferograms and made histograms that showed distribution of phases. Figure 11 shows the histograms. The phases of ocean distribute randomly (Fig. 11(a)), because of the complete decorrelation. The rms value of the phase in the land in the coseismic interferogram is $8^{\circ}$, which corresponds to a displacement error of $3 \mathrm{~mm}$ (Fig. 11(b)). The interferogram of the DEM pair has the rms value of the phase of only $3^{\circ}$, which corresponds to an elevation error of $60 \mathrm{~cm}$ (Fig. 11(c)). These smaller rms value of the phase than before is due to improvements in our processing software, such as improvements in preserving phases and filtering interferogram signals.

Since data in a DEM are sampled, the data cannot represent smaller scale topography than its spacing. Even if grid data of a DEM have no errors, heights (e.g., DEM data) at nongrid points will have errors. The size of these errors depends on the spacing of the DEM. The error of the $1 \mathrm{~km}$ spacing $\mathrm{DEM}$ is $50 \mathrm{~m}$ at most because this region does not have much topography and the highest mountain in the image is $386 \mathrm{~m}$. Therefore, the line-of-sight displacement error due to the DEM error is $(11.8 \times 50 / 210=) 2.8 \mathrm{~cm}$. This is the error of the two-pass differential interferogram.

On the other hand, the error of the four-pass differential interferogram is small, because the spacing is appropriate
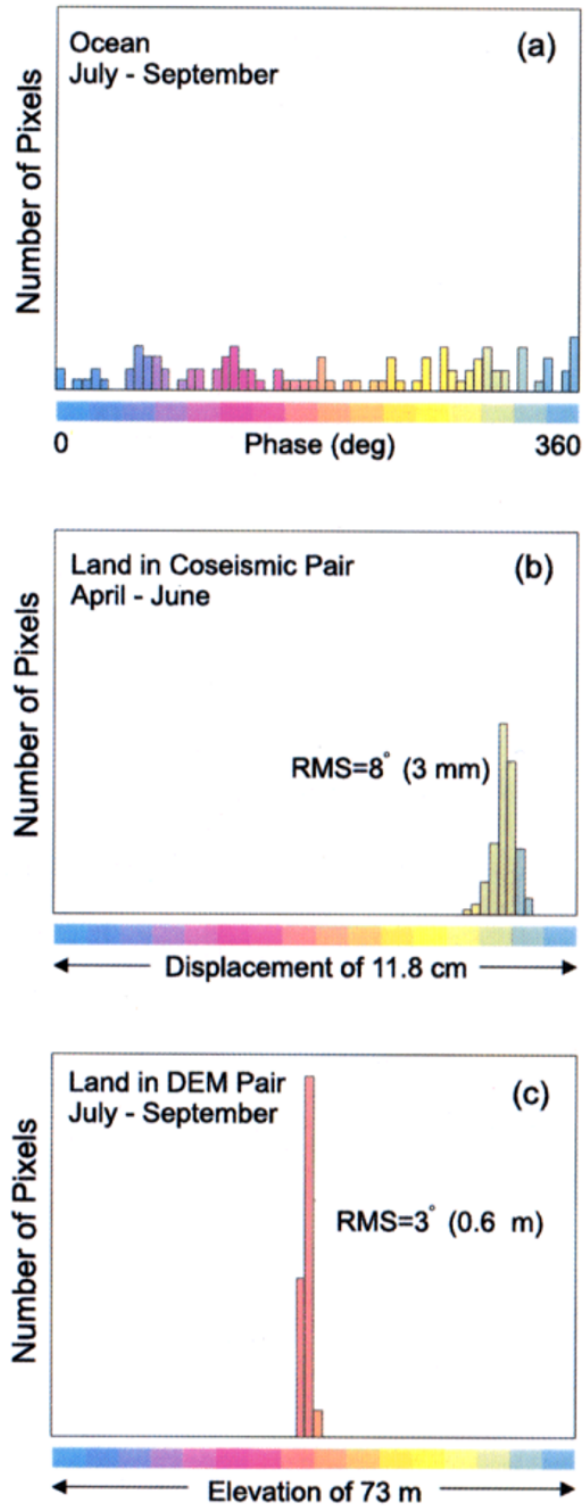

Fig. 11. Histograms of phase distributions. A few hundreds pixels in a rectangle were sampled. (a) Ocean in a interferogram; (b) land in the coseismic interferogram; (c) land in the DEM pair. The phase of the ocean is random because of the complete decorrelation. The phases in the rectangles in interferograms of the coseismic and DEM pairs correspond to constant colors in light green and red, respectively, because of the high correlation.

for the four-pass method and the error of the interferometric DEM is rather small. Because the coherence of the DEM pair is very high everywhere, the phase error is only 0.05 cycle at most (e.g., $\mathrm{rms}=3^{\circ}$ at the sampled rectangle in Fig. 11(c)); this corresponds to $3.7 \mathrm{~m}$ DEM error. In addition, error from propagation anomaly effects is less then 0.25 cycle. Surface changes are estimated as 0.2 cycle at most, because postseismic signals are not seen in Fig. 5. The summed error for the DEM, 0.5 cycles, will be multiplied by the baseline ratio in Eq. (14). The ratio is $257 / 737=0.35$. Thus the displacement error of the four-pass method is 2.1 $\mathrm{cm}$.

Interferometric techniques, such as Very Long Baseline Interferometry, static GPS and SAR Interferometry, will be 
Table 6. JERS-1 excess atmospheric delay from humidity and temperature variations. These values assume a typical incidence angle of $39^{\circ}$, wavelength of $0.2353 \mathrm{~m}$, and latitude of Sakhalin of $53^{\circ}$. The temperature is the average temperature in North Sakhalin in the indicated month. The $30^{\circ} \mathrm{C}$ is for comparison. Delay of $11.77 \mathrm{~cm}$ corresponds to one cycle $(2 \pi)$ phase delay.

\begin{tabular}{lcccc}
\hline & \multicolumn{4}{c}{ Temperature at surface } \\
\cline { 2 - 5 } Change & $\begin{array}{c}\text { April } \\
0^{\circ} \mathrm{C}\end{array}$ & $\begin{array}{c}\text { June, September } \\
12^{\circ} \mathrm{C}\end{array}$ & $\begin{array}{c}\text { July } \\
17^{\circ} \mathrm{C}\end{array}$ & $30^{\circ} \mathrm{C}$ \\
\hline $10 \%$ Humidity & $0.8 \mathrm{~cm}$ & $1.8 \mathrm{~cm}$ & $2.5 \mathrm{~cm}$ & $5.2 \mathrm{~cm}$ \\
$10^{\circ} \mathrm{C}$ Temperature & $0.15 \mathrm{~cm}$ & $0.3 \mathrm{~cm}$ & $0.4 \mathrm{~cm}$ & $0.8 \mathrm{~cm}$ \\
\hline
\end{tabular}

compromised if propagation effects alter the observed phase significantly. Repeat-pass SAR interferometry measures phase differences between two different period over the same area. A common phase bias over all pixels in an interferogram is not measurable by SAR interferometry. Rosen et al. (1996) and Zebker et al. (1997) studied the relation between weather conditions and induced errors. We substituted values that we used for JERS-1 and Sakhalin in their equations. Table 6 shows excess atmospheric delay from humidity and temperature variations, for a typical incidence angle of $39^{\circ}$, wavelength of $0.2353 \mathrm{~m}$, and latitude of Sakhalin of $53^{\circ}$. A relative humidity change of $10 \%$ leads to only $1.8 \mathrm{~cm}$ errors at most in deformation products of the coseismic pair. The low temperature of the surface made the error small. If it were $30^{\circ} \mathrm{C}$, the induced error would be 5.2 $\mathrm{cm}$. Sensitivity to surface temperature change is very low. Temperature change of $10^{\circ} \mathrm{C}$ induces $0.3 \mathrm{~cm}$ errors at most in deformation products of the coseismic pair when there is no net flow of water vapor. This is less than a half of the error $(0.8 \mathrm{~cm})$ at $30^{\circ} \mathrm{C}$. These wet delays mentioned above vary with surface temperature. Thus, areas with low temperatures like Sakhalin survive the errors due to wet delay change much better than areas with high temperature like Hawaii. The line-of-sight change of $82 \mathrm{~cm}$ (see Subsection 3.2) is about 45 and 270 times as large as the error induced by $10 \%$ humidity and $10^{\circ} \mathrm{C}$ temperature change, respectively. The signature of deformation was thus hardly contaminated by humidity nor temperature changes. Change in surface pressure of $10 \mathrm{hPa}$ (=10 millibar) can lead to $2.9 \mathrm{~cm}$ errors in deformation products. The scale of the heterogeneous distribution of variation of pressure between two periods is, however, much larger than the signature of deformation discussed in this paper. Thus, we conclude that the amount of spurious fringes due to the heterogeneous distribution of variation of weather conditions, such as humidity, temperature and pressure, is much smaller than that of the coseismic fringe in our Sakhalin interferogram. This conclusion is consistent with our Sakhalin interferograms, which do not show any spurious signatures that Massonnet and Feigl (1995), Zebker et al. (1997), and Fujiwara et al. (1998) reported.

\section{Conclusions}

We used both the two-pass and four-pass method of differential interferometry to map the displacement field of the 1995 North Sakhalin earthquake. The error of the two- pass interferograms due to using a large $(1 \mathrm{~km})$ spacing DEM is $2.7 \mathrm{~cm}$ at most because of a small perpendicular baseline and the flat terrain of the region. The error of the four-pass interferograms is small $(2.1 \mathrm{~cm})$ because of the excellent correlation of DEM pair and the appropriate balance of the perpendicular baseline length, which reduces the DEM error in the four-pass approach. The four-pass differential interferogram is very similar to the two-pass one. This first comparison of differential interferometry between the two approach proves that both are useful for showing surface displacements using JERS-1 SAR data.

We estimated optimal slip parameters on 12 subfaults using the SAR interferograms. This inversion study of SAR interferogram shows, 1) a rupture area extends to the south of the southernmost rupture trace on the surface, 2) slip varies from one to seven meters from the south to the northern part on a fault plane. The structure of our model is finer than models derived from GPS observations only, because SAR interferograms yield much more information. A theoretical fringe pattern from the model of the earthquake motion was derived. The pattern matches the observations closely.

Correlation study of the Sakhalin interferograms indicates that low surface temperature below freezing point reduced the correlation. Discussion of atmospheric propagation effects of radar signals indicated that the amount of spurious fringes due to the heterogeneous distribution of variations in weather conditions, such as humidity, temperature and pressure, is much smaller than that of the coseismic fringes in our Sakhalin interferogram, due to its low temperature.

We also have presented a map of the postseismic displacement field with the SAR interferometry.

Acknowledgments. The SAR data used in this study were provided by National Space Development Agency of Japan (NASDA) through Remote Sensing Technology Center of Japan (RESTEC). Ministry of International Trade and Industry (MITI) and NASDA retains the ownership of the original SAR data. We are thankful to MITI/NASDA and RESTEC for providing the data. We would like to acknowledge Minoru Kasahara for providing seismic fault positions by GPS point positioning.

\section{References}

Fujiwara, S., P. A. Rosen, M. Tobita, and Mas. Murakami, Crustal deformation measurements using repeat-pass JERS 1 SAR interferometry near the Izu peninsula, Japan, J. Geophys. Res., 103, 24112426, 1998.

Goldstein, R. M., H. Engelhardt, B. Kamb, and R. M. Frolich, Satellite radar interferometry for monitoring ice sheet motion: Application to an Antarctic ice stream, Science, 262, 1525-1530, 1993.

Hiramatsu, A., The shortest discharge tree problem for 2D-image, Memo of Hiramatsu on January 10, 1992, not in print.

Kasahara, M., Summary of study on the 1995 North Sakhalin earthquake and its disaster, Research Report on the 1995 North Sakhalin Earthquake and its Disaster, 1-8, 1996 (in Japanese).

Kikuchi, M., Mechanism analysis by teleseismic body wave inversion, Research Report on the 1995 North Sakhalin Earthquake and its Disaster, 37-43, 1996 (in Japanese).

Massonnet, D. and K. L. Feigl, Discrimination of geophysical phenomena in satellite radar interferograms, Geophys. Res. Lett., 22, 1537-1540, 1995 .

Massonnet, D., M. Rossi, C. Carmona, F. Adragna, G. Peltzer, K. Fiegl, and T. Rabaue, The displacement field of the Landers earthquake mapped by radar interferometry, Nature, 264, 138-142, 1993. 
Massonnet, D., P. Briole, and A. Arnaud, Deflation of Mount Etna monitored by spaceborne radar interferometry, Nature, 375, 567-570, 1995.

Mikhail, E. M., Observations and Least Squares, 497 pp., Harper \& Row, New York, 1976

Murakami, Mak., M. Tobita, S. Fujiwara, T. Saito, and H. Masaharu, Coseismic crustal deformations of 1994 Northridge, California, earthquake detected by interferometry, J. Geophys. Res., 101, 86058614, 1996.

Okada, Y., Surface deformation due to shear and tensile faults in a half space, Bull. Seism. Soc. Am., 75, 1135-1154, 1985.

Ozawa, S., Mak. Murakami, S. Fujiwara, and M. Tobita, Synthetic aperture radar interferogram of the 1995 Kobe earthquake and its geodetic inversion, Geophys. Res. Lett., 24, 2327-2330, 1997.

Rosen, P. A., S. Hensley, H. A. Zebker, F. H. Webb, and E. J. Fielding, Surface deformation and coherence measurements of Kilauea Volcano, Hawaii, from SIR-C radar interferometry, J. Geophys. Res., 101, 23109-23125, 1996.

Shimamoto, T., M. Watanabe, and Y. Suzuki, Surface faults associated with the 1995 Neftegorsk earthquake, Research Report on the 1995 North Sakhalin Earthquake and its Disaster, 203-221, 1996.

Takahashi, M., M. Kasahara, N. Vasilenko, C. U. Kim, A. Ivashenko, F. Kimata, and T. Seno, Coseismic deformation around the northern part of epicentral area of the 1995 North Sakhalin earthquake deduced from geodetic observations, Report on North Sakhalin Earthquake and its Disaster, 27-36 (in Japanese), 191-202 (in English), 1996.

Tobita, M., Mak. Murakami, S. Fujiwara, P. Rosen, S. Hensley, and C. Werner, Correlation studies of JERS-1 SAR interferometry, Abstract of 1996 Earth and Planetary Science Joint Meeting, 87, 1996 (in Japanese).

Zebker, H. A., C. L. Werner, P. A. Rosen, and S. Hensley, Accuracy of topographic maps derived from ERS-1 interferometric radar, IEEE Trans. Geosci. Remote Sens., 32, 823-836, 1994 a.

Zebker, H. A., P. A. Rosen, R. M. Goldstein, A. Gabriel, and C. L. Werner, On the derivation of coseismic displacement fields using differential radar interferometry: The Landers earthquake, J. Geophys. Res., 99, 19617-19634, 1994b.

Zebker, H. A., P. A. Rosen, and S. Hensley, Atmospheric effects in interferometric synthetic aperture radar surface deformation and topographic maps, J. Geophys. Res., 102, 7547-7563, 1997.

M. Tobita (e-mail: tobita@gsi-mc.go.jp), S. Fujiwara, S. Ozawa, P. A. Rosen, E. J. Fielding, C. L. Werner, Mas. Murakami, H. Nakagawa, K. Nitta, and Mak. Murakami 